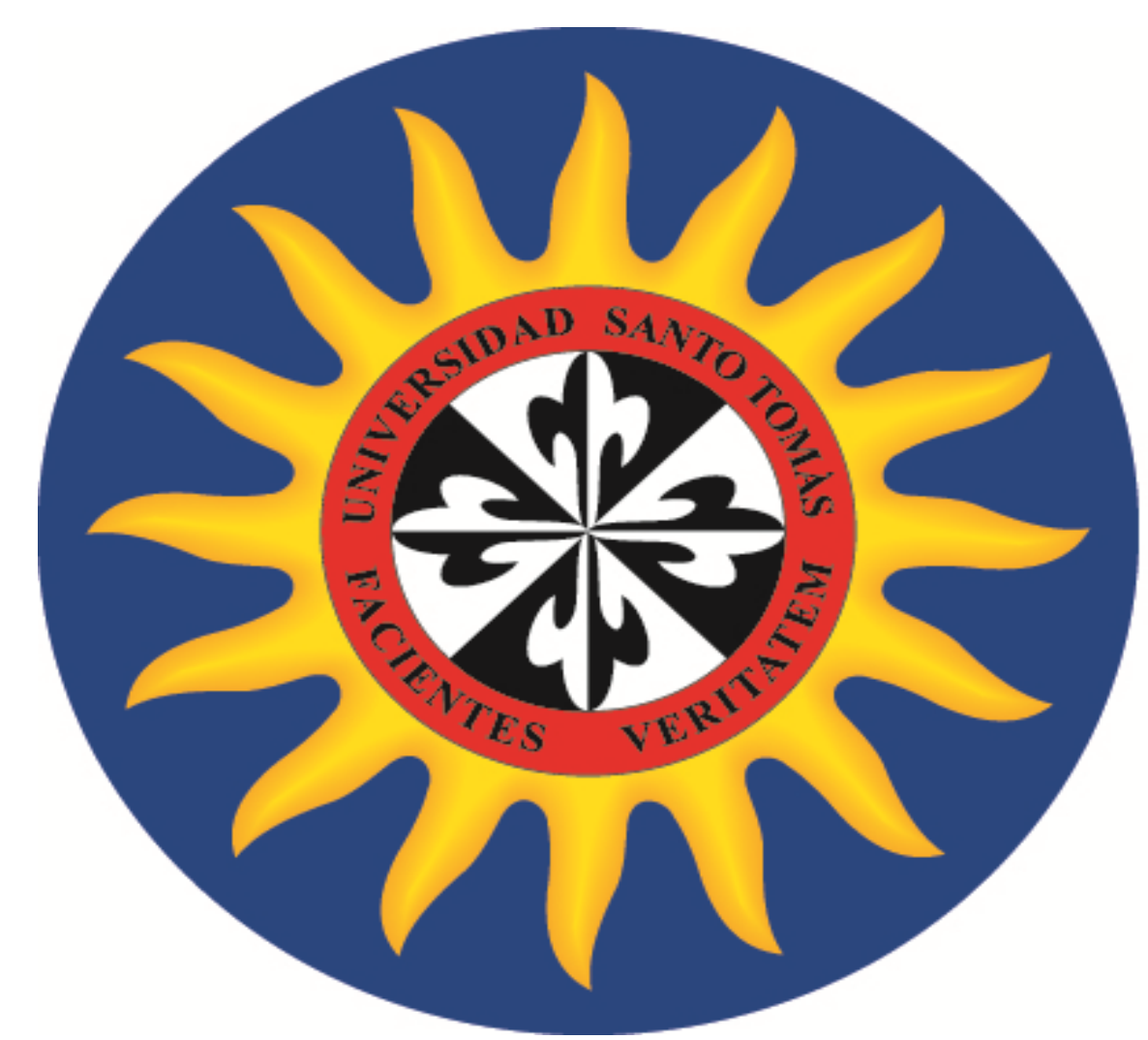

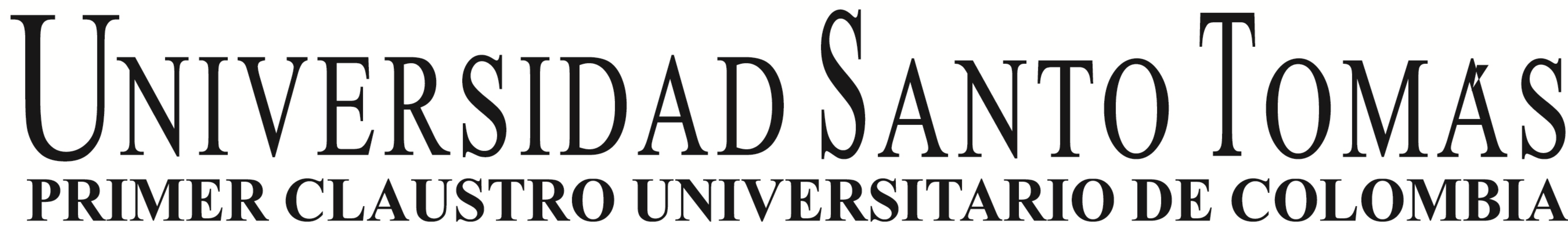

FACULTAD DE MERCADEO Y NEGOCIOS INTERNACIONALES

\section{NEXO FUNCIONAL ENTRE LA RESPUESTA FISIOLÓGICA DE LOS JÓVENES UNIVERSITARIOS FRENTE A LA PREFERENCIA DE MÚSICA PUBLICITARIA Y LOS NIVELES DE RECORDACIÓN DE MARCAS DE BEBIDAS Y ALIMENTOS}

Garzón, C; Sotelo, D; Perea, J; León, C; Gutiérrez, D; Prieto, J; Moreno, M

\section{INTRODUCCIÓN}

厂

a música guarda una estrecha relación con los estados de ánimo y

la generación de recuerdos a largo plazo. Al respecto, Avello, Ga-

vilan y Abril (2011) explican como a través de la música y la voz se

establece una conexión más con el consumidor, que facilita la representación de la marca en su mente y crea asociaciones que activan directamente las emociones, los sentimientos y las experiencias. Lo anterior abre una ventana de posibilidades a nivel del mercadeo y los negocios internacionales, para entender que es precisamente a través del conocimiento del consumidor, cómo las marcas entran a comunicarse e interactuar con el mismo público objetivo. Cada vez que el consumidor recuerda el jingle, inconscientemente asocia el producto, lo que lleva a la decisión de compra y consumo.

\section{HIPÓTESIS}

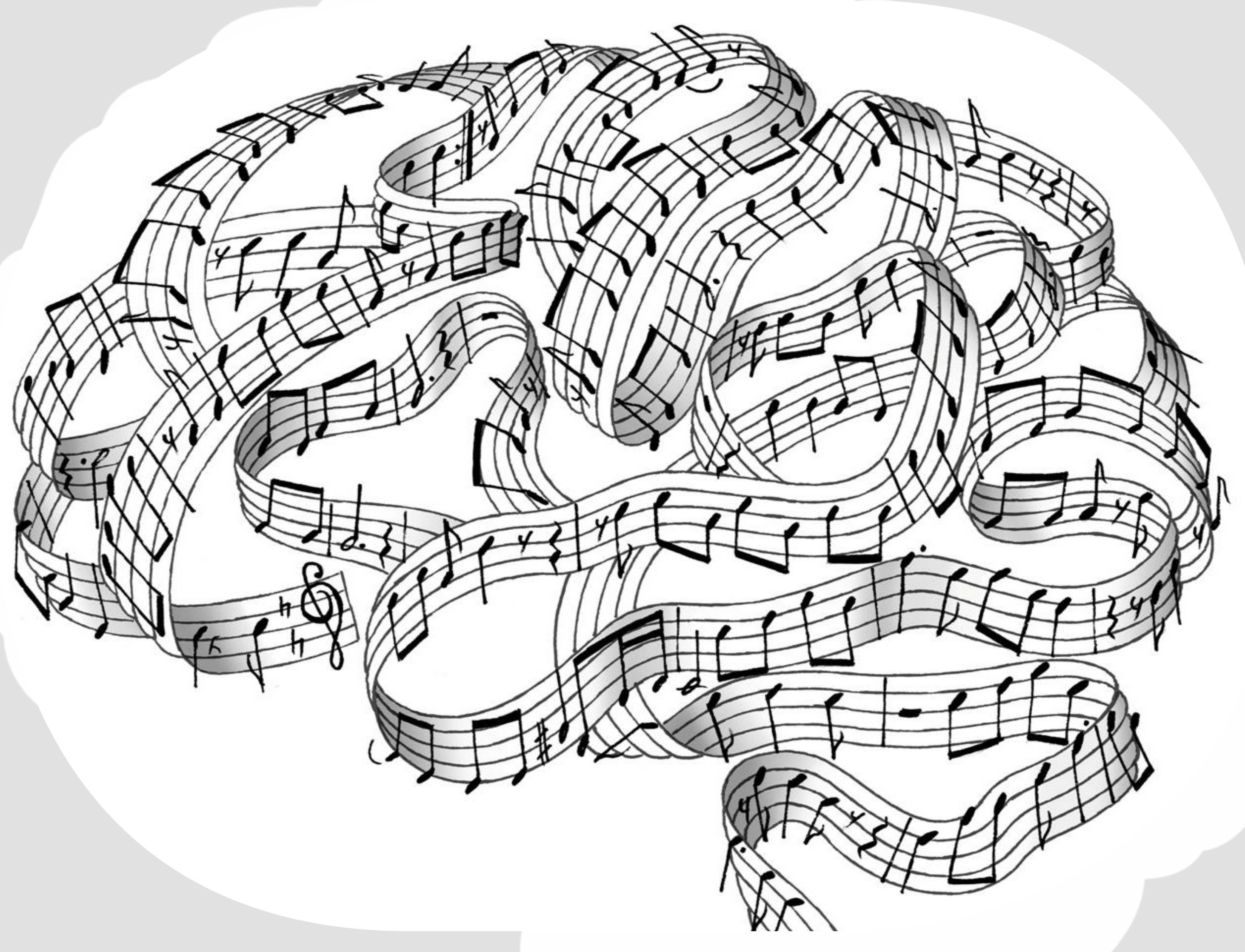

\section{OBJETIVO GENERAL}

Ttablecer el nexo funcional entre la res-

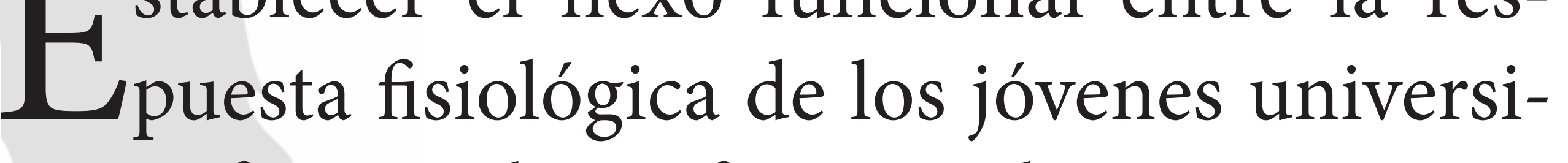
tarios frente a la preferencia de género musical publicitario en los niveles de recordación de marcas de bebidas y alimentos.

\section{METODOLOGÍA}

Diseño experimental:

$\mathrm{U}$ n buen jingle facilita el emplazamiento positivo de una marca de alimentos y bebidas en la mente lo que hace que hayan mayores posibilidades de gustar y recordar en el consumidor.

\section{RESULTADOS}

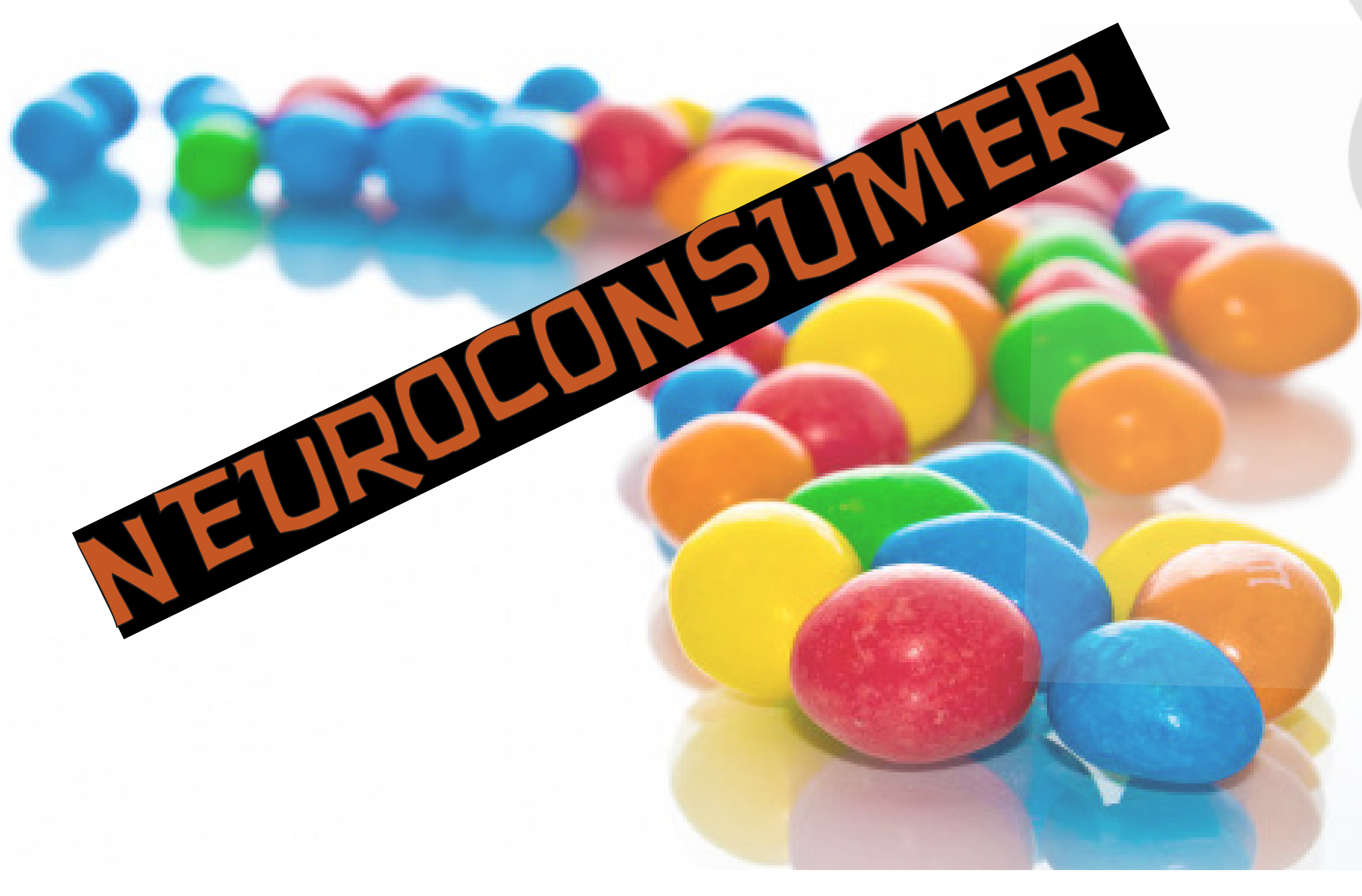

$\mathrm{O}$ btener datos de variación de la respuesta fisiológica, datos sobre la recordación de marcas de bebidas y alimentos, y con estos resultados, generar mayor conciencia social en el mercado y en los consumidores.
Aplicación de una escala de diferencial semántico para evaluar las cualidades sonoras de los jingles, lo que determina la preferen cia de marca.

2

Medición de presión galvánica, encefaloy frecuencia cardiaca de quince (15) jóvenes universitarios frente a la exposición de jingles e imágenes de marcas de bebidas y alimentos.

3 La aplicación de una prueba de memoria 3 por el método de asociación vinculado y de signo para evaluar recordación de marca. 